\title{
Interactions of Postsynaptic Density-95 and the NMDA Receptor 2 Subunit Control Calpain-Mediated Cleavage of the NMDA Receptor
}

\author{
Yi Na Dong, Elisa A. Waxman, and David R. Lynch \\ Departments of Neurology and Pediatrics, University of Pennsylvania and the Children's Hospital of Philadelphia, Philadelphia, Pennsylvania 19104
}

\begin{abstract}
The calcium-dependent protease calpain cleaves the NMDA receptor 2 (NR2) subunit of the NMDA receptor both in vitro and in vivo and thus potentially modulates NMDA receptor function and turnover. We examined the ability of postsynaptic density-95 (PSD-95) protein to alter the calpain-mediated cleavage of NR2A and NR2B. Coexpression of PSD-95 with NMDA receptors in human embryonic kidney 293 cells blocked cleavage of NR2A and NR2B by NMDA receptor-activated calpain. NR2A cleavage by calpain occurred in the cell surface and intracellular fractions and required the presence of NR1 subunits. The blocking effect of PSD-95 did not result from decreased calpain activity, lowered intracellular calcium responses, or the blockade of internalization. Instead, this effect was eliminated by deletion of the C-terminal ESDV motif of NR2A or by overexpression of a palmitoylation-deficient PSD-95 mutant lacking the ability to cluster and to interact with NMDA receptors in situ, suggesting a role for association between the $\mathrm{C}$ terminus of NR2A and clustered PSD-95. Synapseassociated protein 102 , a membrane-associated guanylate kinase interacting with NR2A but lacking palmitoylation motifs and the ability to cluster, did not protect NR2A from cleavage by calpain. Pharmacological inhibition of palmitoylation disrupted the interaction of PSD-95 with NMDA receptors in cortical neurons and allowed NR2A to be cleaved by calpain, whereas NR2A could not be cleaved in untreated neurons. These results indicate that PSD-95 clustering and direct association of NR2A and PSD-95 mediate the blocking effect of PSD-95 on calpain cleavage. PSD-95 could regulate the susceptibility of NMDA receptors to calpain-mediated cleavage during synaptic transmission and excitotoxicity.
\end{abstract}

Key words: glutamate; NMDA receptor; learning; excitotoxicity; PSD-95; protease

\section{Introduction}

NMDA receptors, a subclass of the ionotropic glutamate receptor family, play important roles in synaptic plasticity, memory formation, neural development, and many neurological disorders (Choi, 1988; Collingridge and Lester, 1989; Meldrum and Garthwaite, 1990). These channels are highly permeable to $\mathrm{Ca}^{2+}$ and are generally composed of two types of subunits: the glycinebinding subunit NMDA receptor 1 (NR1) and the glutamatebinding subunits NR2A-D (Hollmann and Heinemann, 1994). Different combinations of these subunits exhibit distinct properties and characteristic regional and developmental expression in vivo (Lynch and Guttmann, 2001). NR2 subunits have large cytoplasmic $\mathrm{C}$ termini that modulate channel activity and localization of NMDA receptors (Mori et al., 1998; Sprengel et al., 1998). The C-terminal region of NR2 subunits is phosphorylated by $\mathrm{Ca}^{2+} /$ calmodulin-dependent protein kinase II, protein kinase C

Received Jan. 19, 2004; revised 0ct. 31, 2004; accepted Nov. 1, 2004.

This work was supported by National Institutes of Health Grants NS39126 and NS45986. DNA core sequencing and calcium imaging were supported by the Mental Retardation Research Center at the Children's Hospital of Philadelphia (CHOP). We thank Margaret Maronski for preparation of neuronal cultures and the CHOP confocal imaging core for aid in confocal microscopy.

Correspondence should be addressed to Dr. David R. Lynch, Division of Neuroscience Research, Children's Hospital of Philadelphia, 502 Abramson Building, Philadelphia, PA 19104-4318. E-mail: lynch@pharm.med.upenn.edu. DOI:10.1523/JNEUROSCI.3722-04.2004

Copyright $\odot 2004$ Society for Neuroscience $\quad$ 0270-6474/04/2411035-11\$15.00/0
(PKC), and protein-tyrosine kinases and contains internalization motifs altering receptor turnover (Kohr and Seeburg, 1996; Omkumar et al., 1996; Grant et al., 1998; Liao et al., 2001; Yang and Leonard, 2001; Scott et al., 2004). C-terminal truncation of NR2 subunits impairs synaptic NMDA receptor localization at hippocampal CA1 synapses and reduces long-term potentiation (Steigerwald et al., 2000; Kohr et al., 2003). These findings suggest that the post-translational modification of the $\mathrm{C}$-terminal domain modulates NMDA receptor function and synaptic localization.

Calpain is a neutral, calcium-dependent protease that is found in neurons in both the cytosol and the synaptic terminal. During synaptic activity, calpain is activated by calcium entry through NMDA receptors (Vanderklish et al., 1995). NR2A-C (but not NR1) are all cleaved in their C-terminal region by calpain in vitro (Bi et al., 1998a,b; Guttmann et al., 2001). In addition, cleavage of NR2A by calpain in situ in transfected human embryonic kidney 293 (HEK293) cells decreases the number of functional NMDA receptors, suggesting that it is involved in NMDA receptor turnover (Guttmann et al., 2002). Cleavage of NR2 subunits (almost exclusively NR2B) is also found after glutamatergic treatment of primary neuronal cultures (Simpkins et al., 2003). The increased solubility of AMPA receptors in rat brain after truncation with calpain suggests that calpain may facilitate the removal of receptors from postsynaptic densities (Lu et al., 2000).

The calpain-cleaved C-terminal region of NR2 subunits inter- 
acts with postsynaptic density-95 (PSD-95), a modular protein enriched in the postsynaptic density. PSD-95 and its homologs contain three 90-amino acid PSD-95/Discs large/zona occludens-1 (PDZ) domains in the N-terminal half of the protein followed by an Src homology 3 domain and a guanylate kinase domain (Cho et al., 1992; Kistner et al., 1993). PSD-95 interacts with the C-terminal $\mathrm{E}(\mathrm{T} / \mathrm{S}) X \mathrm{~V}$ sequence motif of NR2 subunits through the N-terminal PDZ domains (Kornau et al., 1995; Niethammer et al., 1996), a process that may cluster and stabilize NMDA receptors at synapses (Kim et al., 1996). In the present study, we examined the effects of PSD95-NR2 interactions on the cleavage of NR2A and NR2B subunits by calpain to understand whether these interactions may aid in control of NMDA receptor turnover and whether they could explain the selective cleavage of NR2B by calpain in neurons.

\section{Materials and Methods}

Materials. Glutamate, glycine, ketamine, and trypsin were from Sigma (St. Louis, MO); Minimum Essential Medium, penicillin-streptomycin, glutamine, and horse serum were from Invitrogen (Carlsbad, CA). Fetal bovine serum was from HyClone (Logan, UT); dizocilpine (MK-801), ionomycin, and concanavalin A were from Research Biochemicals (Natick, MA). 2-Bromopalmitate, also known as 2-bromohexadecanoic acid, was purchased from Aldrich (Milwaukee, WI). Immobilized monomeric avidin and sulfo- $N$-hydroxysulfosuccinimidyl (NHS)-biotin were from Pierce (Rockford, IL). HEK293 cells were from American Type Culture Collection (Manassas, VA). Calpain inhibitor III (CalI3; MDL 28170; Z-Val-Phe-CHO), caspase inhibitor II (CaspI2; Ac-ValAla-Asp-CHO) and cathepsin inhibitor I (CathI1; Z-Phe-Gly-NHO-Bz) were purchased from Calbiochem (La Jolla, CA). An N-terminal antibody to amino acids 25-130 of NR2C (A-6475) was from Molecular Probes (Eugene, OR). This antibody recognizes NR2A and NR2B (both $170-175 \mathrm{kDa})$ as well as NR2C (135-140 kDa) (Guttmann et al., 2001). An anti-NMDA receptor $2 \mathrm{~B}$ antibody (made to the N-terminal 251 amino acids) was from Zymed (San Francisco, CA). An anti-NMDA receptor $2 \mathrm{~A}$ antibody (made to the last 200 amino acids of the $\mathrm{C}$ terminus) was from Upstate Biotechnology (Lake Placid, NY). AB38, which recognizes calpain-cleaved spectrin, was produced as described previously (Roberts-Lewis et al., 1994). An anti-NR1 monoclonal antibody (made to amino acids 660-811) and an anti-PSD-95 monoclonal antibody (made to amino acids 353-504) were from Transduction Laboratories (Lexington, KY). An anti-actin antibody was from Sigma. The cDNAs for NR2A and NR2B were from rat and mouse, respectively (Lynch et al., 1994; Gallagher et al., 1997).

The following full-length cDNA constructs were donated: rabbit calpastatin from Dr. Masatoshi Maki (Nagoya University, Nagoya, Japan); synapse-associated protein (SAP) 102 from Dr. Richard L. Huganir (Johns Hopkins University, Baltimore, MD); PSD-95 and PSD-95 $(\mathrm{C} 3,5 \mathrm{~S})$ from Dr. David S. Bredt (University of California, San Francisco, $\mathrm{CA})$; and dynamin and dynamin (K44A) from Dr. Sandra L. Schmid (Scripps Clinic, La Jolla, CA).

Preparation of primary neuronal cultures. Primary rat cortical neurons were derived from embryonic day 17 Sprague Dawley rat (Charles River Laboratories, Wilmington, MA) embryos as described previously (Estus et al., 1997). Cortical tissue was dissected and subsequently minced and trypsinized $\left(0.027 \%, 37^{\circ} \mathrm{C}, 7 \% \mathrm{CO}_{2}\right.$ for $\left.20 \mathrm{~min}\right)$, and then washed with $1 \times$ HBSS. Cells were plated in neurobasal medium supplemented with B27 and grown on poly-D-lysine-coated coverslips at a density of $6 \times 10^{5}$ viable cells per $35 \mathrm{~mm}$ culture dish. Cultures were maintained at $37^{\circ} \mathrm{C}$ with $5 \% \mathrm{CO}_{2}$. Non-neuronal cell growth was inhibited with cytosine arabinoside at $7-10 \mathrm{~d}$ in vitro (DIV). Cells were used after at least $14 \mathrm{DIV}$.

Transfection of HEK293 cells. HEK293 cells were grown and transfected using calcium phosphate precipitation as previously described (Grant et al., 1998). Treatments were added $24 \mathrm{hr}$ after transfection. Ketamine (500 $\mu \mathrm{M}$ ) was added to the media during transfection to prevent NMDA receptor activation as previously described (Grant et al., 1998).

Drug treatments. MK- 801 was dissolved in water and used at a final concentration of $100 \mu \mathrm{M}$. Concanavalin A was dissolved in ethanol and used at a final concentration of $0.25 \mathrm{mg} / \mathrm{ml}$. Call3, CaspI2, and CathI1 were dissolved in DMSO and used at 10,3, and $10 \mu \mathrm{M}$, respectively. Final DMSO concentration was $\leq 0.1 \%$.

For studies of calpain cleavage, cells were rinsed twice with $1 \times$ PBS and preincubated for $30 \mathrm{~min}$ in HBSS with MK-801, concanavalin A, protease inhibitors, or vehicle. Glutamate and glycine were then added (100 $\mu \mathrm{M}$ each for routine experiments) for $30 \mathrm{~min}$. For ionomycin treatment, cells were preincubated for $30 \mathrm{~min}$ in HBSS with CalI3 $(10 \mu \mathrm{M})$ or vehicle and followed by $10 \mathrm{~min}$ ionomycin treatment $(1 \mu \mathrm{M})$. For palmitoylation inhibition in cortical neurons, cells were preincubated in HBSS with 2-bromopalmitate $(100 \mu \mathrm{M})$ or vehicle for $10 \mathrm{hr}$ followed by glutamate and glycine treatment. Cells were immediately scraped into $1 \times$ Laemmli stop buffer without bromophenol blue, EGTA, or dithiothreitol (DTT) (Guttmann et al., 2001). Samples were boiled for $5 \mathrm{~min}$, and protein concentrations were determined using the bicinchoninic acid assay (Pierce). Bromophenol blue and DTT were then added, and the samples were stored at $-20^{\circ} \mathrm{C}$ until used.

Truncated forms of NR2A. Truncated forms of NR2A at amino acids 1400 (designated NR2A1400), 1330 (NR2A1330), and 1279 (NR2A1279) were produced previously (Grant et al., 2001; Guttmann et al., 2001). NR2A1460, which lacks the last four amino acids (ESDV) of the C terminus, was made by PCR by priming NR2A in prk7 with the forward oligonucleotide (5'-ACCTACATGAAAACCAAAGCAAGT-3') and the reverse oligonucleotide (5' $5^{\prime}$ TGATGGAAGATCTTAAACATCAGATTAGATACTAGGCAT-3'). The sample was digested with BglII, ligated into NR2A, and then subcloned into prk7. The mutation was verified by nucleotide sequencing using an ABI 3700 automated genetic analyzer (Molecular Biology Core at the Children's Hospital of Philadelphia).

Western blotting. Thirty micrograms of total protein were loaded on an $8 \%$ polyacrylamide gel (10\% for experiments examining PSD-95). After SDS gel electrophoresis, proteins were transferred to nitrocellulose, blocked with $3 \%$ dry milk, and incubated with primary antibody. Blots were then incubated with appropriate HRP-conjugated secondary antibodies and developed with enhanced chemiluminescence (Pierce). Each blot was scanned using an Epson scanner in conjunction with Adobe Photoshop (Guttmann et al., 2001). Data were quantitated using imaging densitometry and analyzed using the NIH Image program.

Calcium imaging. For calcium imaging, cells were cotransfected with green fluorescent protein (GFP) to identify transfected cells. Eighteen to $20 \mathrm{hr}$ after transfection, cells were rinsed twice with HBSS. The medium was then replaced with HBSS containing $2 \mu \mathrm{M}$ fura- $2 \mathrm{AM}$ and returned to the incubator. After a $30 \mathrm{~min}$ incubation, cells were rinsed twice with HBSS and placed on the stage of an Eclipse TE300 microscope (Nikon, Melville, NY). Images of cells were obtained and analyzed using the Metafluor imaging system (Universal Imaging, Downingtown, PA). Calibrations were completed as previously described (Lynch et al., 2001), and all GFP-expressing cells in a given field were measured. Before agonist application, images were obtained for several minutes to establish a stable baseline calcium measurement. Agonists (100 $\mu \mathrm{m}$ glutamate and $100 \mu \mathrm{M}$ glycine) were then applied, and images were obtained at $1 \mathrm{sec}$ intervals. Peak calcium concentrations were typically observed within 30 $\mathrm{sec}$, and resting calcium levels were typically 60-100 nм.

Coimmunoprecipitation. Briefly, HEK293 cells or cortical neuronal cultures (22-24 DIV) were rinsed twice with PBS after treatment and then scraped into $1 \mathrm{ml}$ of lysis buffer containing $1 \mathrm{~mm}$ EDTA, $150 \mathrm{~mm}$ $\mathrm{NaCl}, 100 \mathrm{~mm}$ Tris $\mathrm{HCl}, 1 \%$ Triton X-100, 0.5\% sodium deoxycholate, $0.25 \mathrm{~mm}$ PMSF, $1 \mu \mathrm{g} / \mathrm{ml}$ aprotinin, $1 \mu \mathrm{g} / \mathrm{ml}$ leupeptin, and $1 \mathrm{~mm}$ iodoacetamide. After centrifugation at 12,500 rpm in a Microfuge for $20 \mathrm{~min}$, the lysate was incubated with $40 \mu \mathrm{l}$ of protein $\mathrm{G}$ beads for $2 \mathrm{hr}$ at $4^{\circ} \mathrm{C}$ to remove any proteins that would bind nonspecifically to the beads. After brief centrifugation, the supernatant from HEK293 cells was incubated with an anti-NR2C antibody (A-6475, which recognizes NR2A-C) (dilution, 1:100). The supernatant from cortical neuronal cultures was incubated with an anti-NR2A antibody (dilution, 1:100) overnight at $4^{\circ} \mathrm{C}$. Twenty-five microliters of protein $\mathrm{G}$ beads were then added to the solution and incubated at $4^{\circ} \mathrm{C}$ for $2 \mathrm{hr}$. The beads were washed four times with lysis buffer followed by $15 \mathrm{~min}$ centrifugation at 12,500 rpm. Sample buffer for SDS-PAGE was added, and the mixture was boiled for 5 min. 
Beads were pelleted by centrifugation, and a fixed volume of supernatant was applied to SDS-PAGE $8 \%$.

Biotinylation. After treatment, HEK293 cells were placed on ice and rinsed twice with a cold rinsing solution containing PBS, pH 7.5, $1 \mathrm{~mm}$ $\mathrm{MgCl}_{2}$, and $0.1 \mathrm{~mm} \mathrm{CaCl}_{2}$ (Simpkins et al., 2003). Cells were then gently agitated at $4^{\circ} \mathrm{C}$ for $20 \mathrm{~min}$ in rinsing solution containing $1 \mathrm{mg} / \mathrm{ml} \mathrm{NHS}$ biotin. Cells were rinsed twice in quenching solution (rinsing solution with $100 \mathrm{~mm}$ glycine added) and agitated at $4^{\circ} \mathrm{C}$ in quenching solution with $10 \mu \mathrm{M}$ MK-801 for $20 \mathrm{~min}$. Cells were washed and agitated for $1 \mathrm{hr}$ at $4^{\circ} \mathrm{C}$ in radioimmunoprecipitation assay (RIPA) buffer $[150 \mathrm{~mm} \mathrm{NaCl}$, 1 mм EDTA, 100 mm Tris HCl, pH 7.4, 1\% (v/v) Triton X-100, 1\% (w/v) deoxycholate, and $0.1 \%(\mathrm{w} / \mathrm{v})$ SDS] containing protease inhibitors (1 $\mu \mathrm{g} / \mathrm{ml}$ leupeptin, $250 \mu \mathrm{M}$ PMSF, $1 \mu \mathrm{g} / \mathrm{ml}$ aprotinin, $1 \mathrm{mg} / \mathrm{ml}$ trypsin inhibitor, and $1 \mathrm{~mm}$ iodoacetamide). Samples were harvested and centrifuged at $12,400 \mathrm{rpm}$ for $20 \mathrm{~min}$ at $4^{\circ} \mathrm{C}$. Separate aliquots of the lysate were taken for total lysate fraction, protein quantification, and incubation in avidin beads overnight at $4^{\circ} \mathrm{C}$. After overnight incubation, samples were centrifuged at 12,400 rpm for $15 \mathrm{~min}$ in a Microfuge, and the supernatant (the intracellular fraction) was removed. Sample solubilizing buffer $(4 \times$; $8 \%$ SDS, 240 mm Tris, pH 6.8, 0.04\% bromophenol blue, 40\% glycerol, and 4\% 2-mercaptoethanol) was added to both the total lysate and intracellular fractions. Avidin beads were then washed four times with RIPA buffer and incubated in $2 \times$ sample solubilizing buffer for $30 \mathrm{~min}$ at room temperature. Samples were then centrifuged for $5 \mathrm{~min}$ at 12,000 rpm, and the supernatant (the extracellular fraction) was removed and stored at $-20^{\circ} \mathrm{C}$. Thirty micrograms of each fraction were subjected to SDS-PAGE and Western blot analysis.

Immunofluorescence microscopy. HEK293 cells were transfected with NR1a and NR2A in combination with PSD-95 or PSD-95 $(C 3,5 S)$ in the presence of $100 \mu \mathrm{M}$ MK-801. Twenty-four hours after transfection, cells were fixed with ice-cold methanol for $10 \mathrm{~min}$ at $-20^{\circ} \mathrm{C}$. After blocking with $0.2 \%$ BSA and $0.1 \%$ Triton X-100 in OptiMEM, coverslips were incubated for $2 \mathrm{hr}$ at room temperature with antibodies to NR2A (Nterminal antibody A-6475; 1:200) and PSD-95 (1:200), followed by FITC-conjugated goat anti-rabbit (for NR2A) and rhodamineconjugated anti-mouse (for PSD-95) secondary antibodies (1:200; The Jackson Laboratory, Bar Harbor, ME) for $1 \mathrm{hr}$ at room temperature. Cells were then washed and mounted using Vectorshield with 4',6-diamidino2-phenylindole (Vector Laboratories, Burlingame, CA). Fluorescent pictures were taken using a Leica (Nussloch, Germany) DM IRE2 HC fluo TCS 1-B-UV microscope coupled to a Leica TCS SP2 spectral confocal system/UV. The scan head contains an acousto-optical beam splitter for simultaneous control of up to six laser lines. The three fluorochromes were sequentially scanned with all conditions at identical exposures. Each picture is representative of five samples.

Data analysis. All data were analyzed using Instat software. Statistics were performed by ANOVA or $t$ tests, and significance was set at $p<0.05$. Data were expressed as means \pm SEM.

\section{Results \\ Effect of PSD-95 on calpain-mediated cleavage of NR2 subunits}

To assess the ability of PSD-95 to alter the cleavage of NR2A by calpain, HEK293 cells cotransfected with the NR1a/2A combination and PSD-95 or vector control were incubated in glutamate and glycine and analyzed by Western blots using an N-terminal antibody that recognizes NR2A in transfected cells (Guttmann et al., 2002). As reported in our previous study, agonist stimulation of NMDA receptors caused a $46 \%$ decrease in full-length NR2A immunoreactivity $(n=8 ; p=0.0008)$ (Fig. $1 A, B)$, which was inhibited by the inclusion of the NMDA receptor antagonist MK$801(n=8 ; p=0.0055)$ (Fig. $1 A, B)$. No degradation product was observed after agonist stimulation, suggesting that the cleavage products are not stable in this system (Guttmann et al., 2002). The degradation of full-length NR2A was inhibited by coexpression of calpastatin, a protein calpain inhibitor, showing that the cleavage of NR2A results from the activation of calpain. When
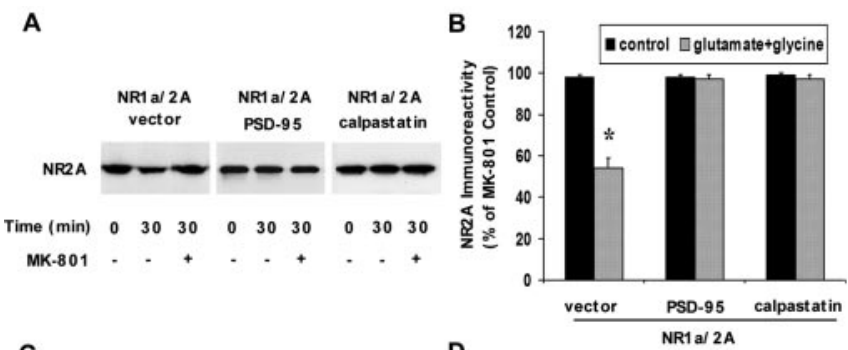

C
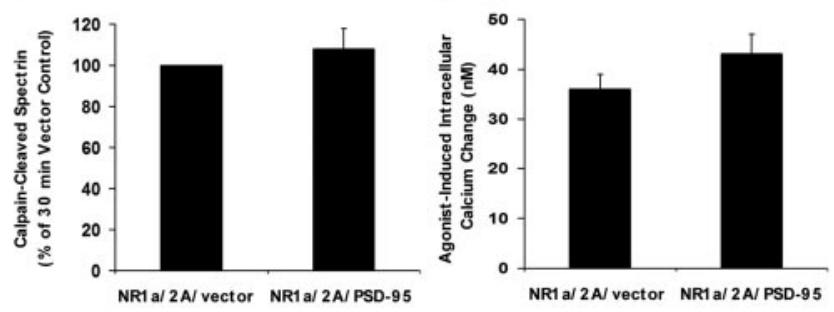

Figure 1. Effects of PSD-95 on calpain-mediated cleavage of the NR2A subunit. HEK293 cells were transfected with NR1a, NR2A, and PSD-95, calpastatin, or vector control and treated with $100 \mu \mathrm{m}$ glutamate and $100 \mu \mathrm{m}$ glycine in the presence or absence of $100 \mu \mathrm{m}$ MK- 801 for 0 or 30 min. NMDA receptor activation resulted in a significant decrease in full-length NR2A immunoreactivity $(A$, representative Western blots of NR2A) as confirmed by quantification of NR2A levels $(B)$ (N-terminal antibody A-6475; * $p=0.0008 ; n=8$ ). Coexpression of PSD-95 or calpastatin inhibited the reduction in NR2A immunoreactivity. No proteolysis of NR2A was observed when NMDA receptor activity was blocked by addition of MK-801. Quantitated data are expressed as a percentage of the MK- 801 control condition. C, Calpain activity was measured after 30 min agonist treatment by assessment of a calpain-generated spectrin degradation product as detected by an antibody to this product (AB38); coexpression of PSD-95 had no effect on the production of calpain-cleaved spectrin compared with the vector control ( $p=0.2441$; $n=5)$. $D$, No difference was observed between intracellular calcium responses of NR1a/2A cells cotransfected with PSD-95 or vector control $(p=0.1709 ; n=14)$. Data are shown as mean \pm SEM (error bars)

transfected with PSD-95, the degradation of full-length NR2A was also completely abolished (Fig. $1 A, B$ ). No systematic difference was noted between baseline (before agonist application) expression levels of NR2A immunoreactivity in the presence or absence of PSD-95 (data not shown). These data indicate that activation of calpain by NMDA receptor stimulation leads to the cleavage of NR2A, an effect that was eliminated by coexpression of PSD-95.

To rule out the possibility that PSD-95 expression directly inhibits calpain activity in HEK293 cells, we examined the levels of a calpain-generated spectrin degradation product after $30 \mathrm{~min}$ agonist stimulation using an antibody (AB38) selective for this product (Roberts-Lewis et al., 1994; Simpkins et al., 2003). Levels of the spectrin degradation product were similar in cells with and without PSD-95 ( $n=5 ; p=0.2441)$ (Fig. $1 C)$, indicating that the effect of PSD-95 on calpain-mediated cleavage of NR2A is not attributable to globally decreased calpain activity. Coexpression of PSD-95 has been reported to lower the whole-cell current responses of NR1a/2A by decreasing their sensitivity to glutamate (Rutter and Stephenson, 2000), suggesting that PSD-95 could eliminate the calpain-mediated cleavage of NR2A by lowering the intracellular calcium response to agonists. In our treatment conditions, which include maximal stimulation by agonists, the presence of PSD-95 did not significantly lower the intracellular calcium response compared with the vector control $(n=14 ; p=$ 0.1709) (Fig. $1 D$ ), indicating that the blocking effect of PSD-95 on calpain-mediated NR2A cleavage is not mediated through a decrease in the intracellular calcium response to agonists.

Our previous study demonstrated that NR2B was also de- 
A

C

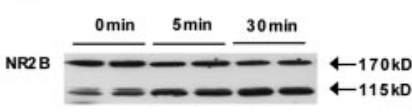

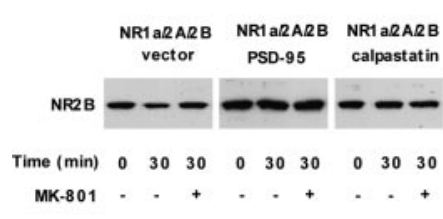

B

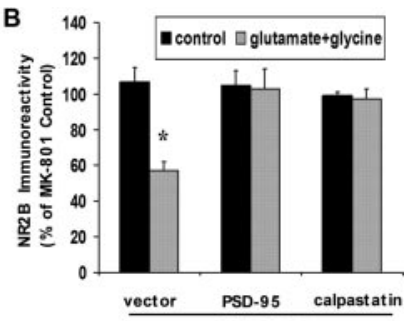

D

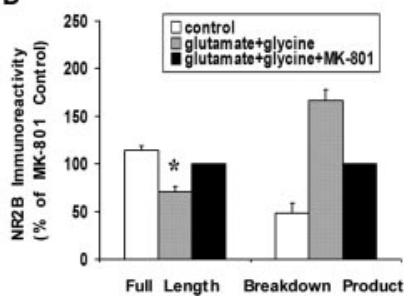

Figure 2. Effects of PSD-95 on calpain-mediated cleavage of the NR2B subunit. $A$, Representative Western blots of NR2B from HEK293 cells cotransfected with NR1a, NR2A, NR2B, and PSD-95, calpastatin, or vector control and treated with $100 \mu \mathrm{m}$ glutamate and $100 \mu \mathrm{m}$ glycine in the presence or absence of $100 \mu \mathrm{m}$ MK-801 for 0 or $30 \mathrm{~min}$. B, Quantification of NR2B levels. Agonist treatment resulted in the significant degradation of NR2B ( $\mathrm{N}$-terminal antibody to NR2B; ${ }^{*} p=0.0157 ; n=5$ ). Coexpression of PSD-95 or calpastatin inhibited the reduction in NR2B immunoreactivity. No stable breakdown product of NR2B was observed subsequent to calpain activation. $C$, Representative Western blots of NR2B from cultured cortical neurons treated with $100 \mu \mathrm{m}$ glutamate and $100 \mu \mathrm{m}$ glycine for 5 or $30 \mathrm{~min}$. D, Quantification of NR2B levels. Agonist treatment decreased the level of full-length NR2B and increased the level of an $\mathrm{N}$-terminal breakdown product ( $115 \mathrm{kDa}$ ) compared with 0 min (N-terminal antibody to NR2B; $n=6 ; p=0.0049$ for full-length NR2B; 0 vs $30 \mathrm{~min} ; p=0.0057$ for NR2B breakdown product; 0 vs $30 \mathrm{~min}$ ). The inclusion of MK- 801 prevented the loss of full-length NR2B and the increase in the NR2B breakdown product. NR2B immunoreactivity was quantitated as a percentage of the MK-801 control condition. Data are shown as mean \pm SEM (error bars).

graded by calpain in transfected HEK293 cells but only if the NR2A subunit was present to facilitate calpain activation (Simpkins et al., 2003). To examine the ability of PSD-95 to alter the cleavage of NR2B, HEK293 cells cotransfected with the NR1a/ $2 \mathrm{~A} / 2 \mathrm{~B}$ combination and PSD-95 or vector control were treated with glutamate and glycine and analyzed by Western blots. Agonist stimulation of these cells caused a $43 \%$ decrease in full-length NR2B immunoreactivity using an antibody to the N-terminal region of NR2B $(n=5 ; p=0.0157)$ (Fig. $2 A, B)$; this decrease was inhibited by the inclusion of the NMDA receptor antagonist MK$801(n=5 ; p=0.0027)$ (Fig. $2 A, B)$. Coexpression of PSD-95 or calpastatin eliminated the degradation of NR2B, showing that calpain mediates the degradation of NR2B and that PSD-95 also protects NR2B from calpain-mediated cleavage. Although an N-terminal degradation product of NR2B containing approximately 1050 amino acids was found in cultured hippocampal neurons subsequent to agonist stimulation (Fig. 2C,D) (Simpkins et al., 2003), no degradation product was identified in transfected HEK293 cells using this N-terminal antibody, showing that the $\mathrm{N}$-terminal fragments of calpain-mediated degradation of NR2B (like those of NR2A) are not stable in HEK293 cells. In contrast, the degradation product of NR2B in neurons was present under basal conditions (as noted in our previous study) and rapidly increased in amount within at most several minutes after NMDA receptor activation (Fig. 2C,D), consistent with ongoing calpain activity in neuronal culture.

Effects of PSD-95 on the cleavage of shortened forms of NR2A by calpain

To understand the mechanism of the modulation of calpainmediated cleavage of the NR2A subunit by PSD-95 and to iden-

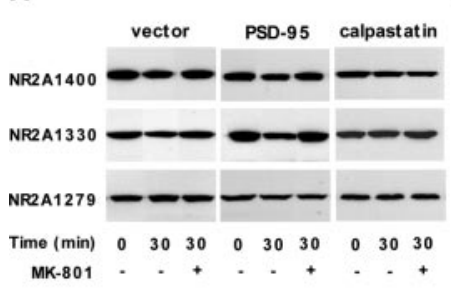

C
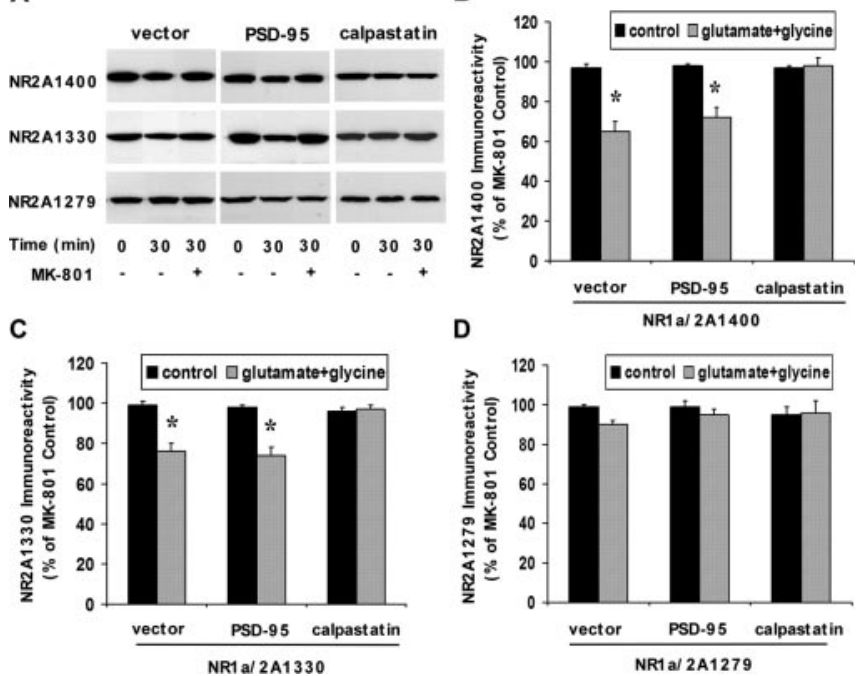

D

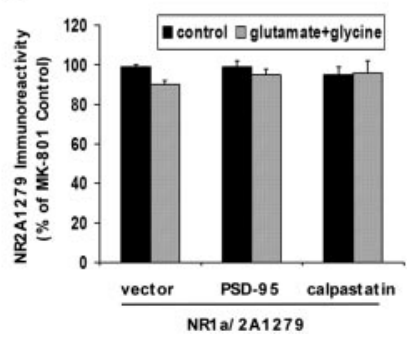

Figure 3. Effects of PSD-95 on the cleavage of shortened forms of NR2A by calpain. A, Representative Western blots of NR2A1400, NR2A1330, and NR2A1279 from HEK293 cells cotransfected with NR1 a and PSD-95, calpastatin, or vector control and treated with $100 \mu \mathrm{m}$ glutamate and $100 \mu \mathrm{m}$ glycine in the presence or absence of $100 \mu \mathrm{m}$ MK-801 for 0 or $30 \mathrm{~min}$. B, Quantification of NR2A1400 levels. Agonist treatment of cells cotransfected with NR1a/NR2A1400 resulted in the significant degradation of NR2A1400 ( $N$-terminal antibody A-6475; ${ }^{*} p=0.0001$; $n=6$ ). Coexpression of calpastatin inhibited the reduction in NR2A1400 immunoreactivity, but the presence of PSD-95 had no effect $\left({ }^{*} p=0.0023 ; n=4\right)$. C, Quantification of NR2A1330 levels. Agonist treatment of cells cotransfected with NR1a/NR2A1330 resulted in the significant degradation of NR2A1330 (N-terminal antibody A-6475; ${ }^{*} p=0.0037 ; n=8$ ). Coexpression of calpastatin inhibited the reduction in NR2A1330 immunoreactivity, but the presence of PSD-95 had no effect $\left({ }^{*} p=0.0149 ; n=7\right)$. D, Quantification of NR2A1279 levels. No detectable change in NR2A1279 immunoreactivity was observed after agonist treatment ( $p=0.1767$; $n=5$ ). No difference was seen after coexpression of calpastatin or PSD-95. Quantitated data are expressed as a percentage of the MK-801 control condition. Data are shown as mean \pm SEM (error bars).

tify the exact sites of NR2A cleavage in situ, shortened forms of the NR2A subunit containing different potential calpain cleavage sites were coexpressed in HEK293 cells with NR1a and PSD-95 or vector control. Receptors containing these forms have similar ligand-binding characteristics and produce intracellular calcium transients similar to those of wild-type NR1a/2A (Grant et al., 1998; Anegawa et al., 2000; Guttmann et al., 2001). In addition, receptors containing shortened forms of NR2A (such as NR2A truncated to amino acid 1051) still activate calpain after NMDA receptor stimulation (Guttmann et al., 2002). As shown in Figures $3, A$ and $B$, and $4 D$, NMDA receptor activation by glutamate and glycine decreased NR2A1400 immunoreactivity by $35 \%$ compared with the 0 min control $(n=6 ; p=0.0001)$. Coexpression of calpastatin inhibited the degradation of NR2A1400, confirming that this effect is calpain-mediated. Coexpression of PSD-95 did not prevent this degradation (28\% of the 0 min control) $(n=4 ; p=0.0023)$. When we used NR2A truncated to amino acid 1330, NR2A1330 was still cleaved by calpain (Figs. $3 A, C, 4 D)(n=8 ; p=0.0037)$. The decrease in NR2A1330 immunoreactivity reached $24 \%$ of the 0 min control, somewhat smaller than that found with wild-type NR2A. Coexpression of calpastatin inhibited the degradation of NR2A1330, but coexpression of PSD-95 had no effect (26\% decrease from the $0 \mathrm{~min}$ control) $(n=7 ; p=0.0149)$. In contrast, when cells were transfected with NR1a/2A1279, no detectable change in NR2A1279 immunoreactivity was observed after glutamate and glycine treatment ( $p=0.1767, n=5$ ) (Figs. $3 A, D, 4 D$ ). Similarly, no difference was seen with coexpression of calpastatin or PSD-95. 


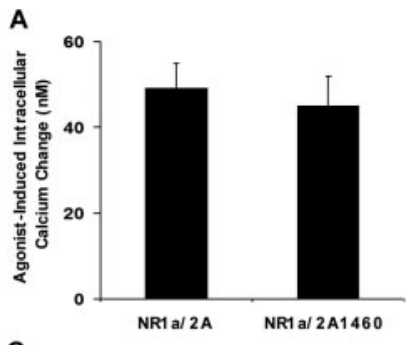

C

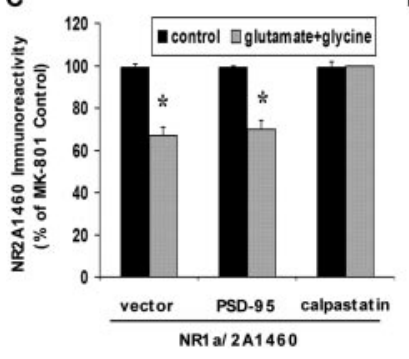

B
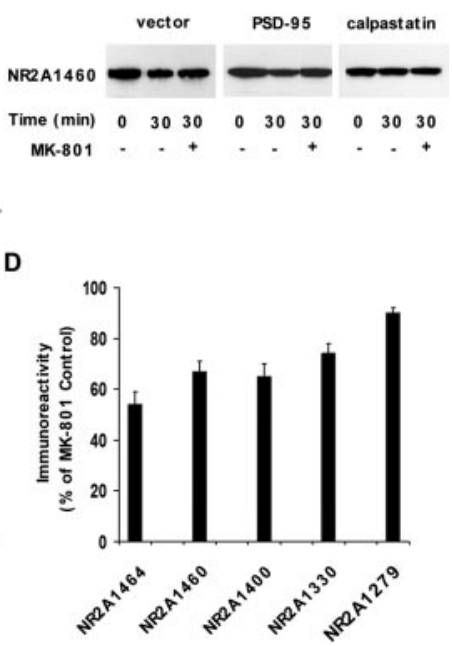

Figure 4. Interaction of the ESDV motif with PSD-95 in NR2A cleavage by calpain. A, NR1a/ $2 A 1460$ produced agonist-induced intracellular calcium transients similar to those of wild-type NR1a/2A $(n=10 ; p=0.6632)$. B, Representative Western blots of NR2A1460 from HEK293 cells cotransfected with NR1a and PSD-95, calpastatin, or vector control and treated with 100 $\mu \mathrm{m}$ glutamate and $100 \mu \mathrm{m}$ glycine in the presence or absence of $100 \mu \mathrm{m}$ MK- 801 for 0 or $30 \mathrm{~min}$. C, Quantification of NR2A1460 levels. NMDA receptor activation resulted in the significant degradation of NR2A1460 (N-terminal antibody A-6475; ${ }^{*} p=0.0002 ; n=5$ ). Coexpression of calpastatin inhibited the reduction in NR2A1460 immunoreactivity, but the presence of PSD-95 had no effect $\left({ }^{*} p=0.0002 ; n=5\right)$. NR2A1460 immunoreactivity was quantitated as a percentage of the MK-801 control condition. Data are mean \pm SEM (error bars). D, The histogram summarizes the different cleavage patterns of NR2A and NR2A mutants by calpain in HEK293 cells. One hundred micromolar glutamate and $100 \mu \mathrm{m}$ glycine treatment for $30 \mathrm{~min}$ resulted in $46,33,35$, and 24\% decreases in NR2A, NR2A1460, NR2A1400, and NR2A1330 immunoreactivity, respectively. No significant cleavage in NR2A1279 was detected. Immunoreactivity of NR2A and NR2A mutants was quantitated as a percentage of the MK-801 control condition. Data are expressed as mean \pm SEM (error bars).

These results provide in situ evidence that all NR2A calpain cleavage sites are located on the C-terminal side of amino acid 1279, consistent with the two calpain cleavage sites for NR2A identified in vitro at amino acids 1279 and 1330 (Guttmann et al., 2001). Furthermore, PSD-95 had no effect on the calpain-mediated cleavage of NR2A1330 and NR2A1400, showing that the effect of PSD-95 was mediated through the final 64 amino acids of NR2A.

Because PSD-95 binds to the NR2A subunit via the ESDV motif at the extreme C terminus (Kornau et al., 1995; Niethammer et al., 1996), a direct interaction in this location could modulate the cleavage of NR2A by calpain. We then examined the effects of PSD-95 on cleavage of mutant NR2A lacking only the C-terminal four amino acid residues (ESDV; denoted as NR2A1460). This construct produced agonist-induced intracellular calcium transients similar to those of wild-type NR1a/2A $(n=10 ; p=0.6632)$ (Fig. $4 A)$. When HEK293 cells transfected with NR1a/2A1460 were treated with glutamate and glycine, NR2A1460 immunoreactivity significantly decreased (33\% of the 0 min control) $(n=5 ; p=0.0002)$ (Fig. $4 B-D)$; the degradation of NR2A1460 was inhibited by the inclusion of MK-801 $(n=5$; $p=0.0004$ ) and by coexpression of calpastatin. These data show that calpain mediates the degradation of NR2A1460 and that receptors containing this truncated form of NR2A activate calpain. However, the presence of PSD-95 had no effect on the degradation of NR2A1460 (30\% of the 0 min control) $(n=5 ; p=$ 0.0002). This further confirms that PSD-95 does not inhibit calpain activation in this system and demonstrates that the
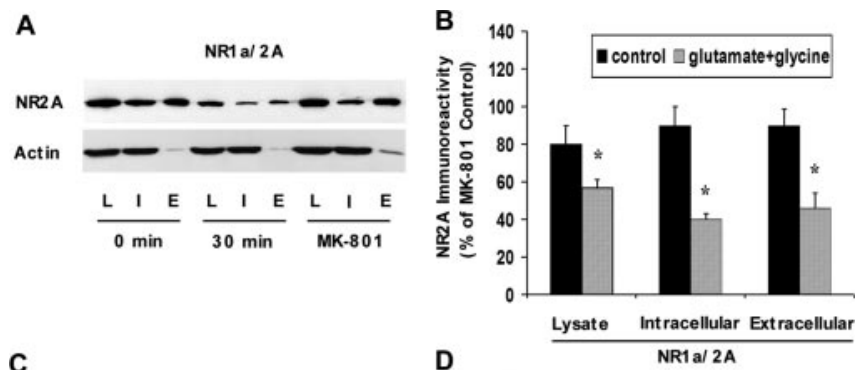

C
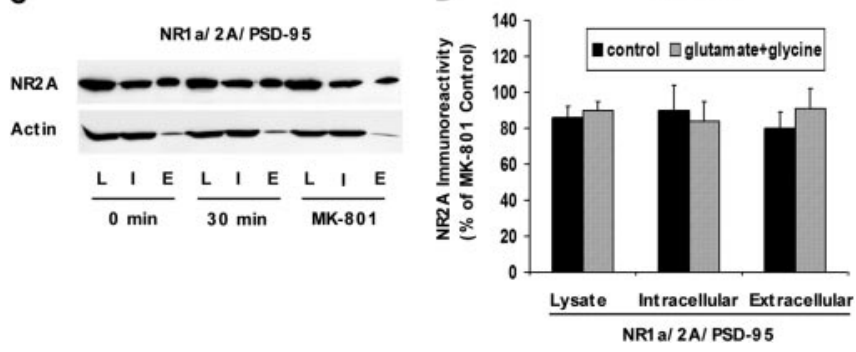

Figure 5. Location of the calpain-mediated cleavage of NR2A in HEK293 cells. HEK293 cells cotransfected with the NR1a/2A combination were preincubated with $100 \mu \mathrm{m}$ glutamate and glycine in the presence or absence of $100 \mu \mathrm{M}$ MK-801 for 0 or $30 \mathrm{~min}(n=8)$ and then labeled with NHS-biotin under nonlytic conditions. The extracellular and intracellular fragments were separated and subjected to Western blotting with an N-terminal antibody for NR2A (A-6475). The amount of immunoreactivity in the lysate $(\mathrm{L})$, extracellular $(\mathrm{E})$, and intracellular $(\mathrm{I})$ fractions was quantified as a percentage of the MK-801 control condition. A representative Western blot and bar graph $(A, B)$ demonstrate a reduced level of NR2A immunoreactivity in the intracellular fraction ( $50 \%$ decrease from the 0 min control) $(n=8 ; p=0.0166)$ and extracellular fraction ( $45 \%$ decrease from the 0 min control) $(n=8 ; p=0.0172)$. An anti-actin antibody confirmed that actin remains primarily in the intracellular fraction, with $90-95 \%$ of actin appearing in the intracellular fraction, as shown by a representative blot $(A)$, showing that membrane integrity was preserved. Cotransfection with PSD-95 prevented the loss of NR2A in both the intracellular and extracellular fractions ( $n=7 ; p=0.4754$ for intracellular fraction; $p=0.9247$ for extracellular fraction) $(C, D)$. Data are shown as mean \pm SEM (error bars).

C-terminal ESDV motif of NR2A is essential for the blockade of calpain-mediated cleavage of NR2A subunit by PSD-95.

\section{Cellular location of calpain-mediated cleavage in HEK cells and effects of receptor assembly}

Although the data demonstrate the need for the structural components that mediate direct NR2A-PSD-95 interaction in the blockade of calpain-mediated cleavage by PSD-95, they do not completely define the mechanism of this event or the cellular location of calpain-mediated cleavage. As the level of cleavage by calpain approaches $50 \%$ of the total NR2, this suggests that calpain might act not only at the cell surface but also at other cellular locations. We sought to assess this by examining the amount of intracellular and extracellular cleavage using biotinylation. HEK293 cells cotransfected with the NR1a/2A combination and PSD-95 or vector control were treated with glutamate and glycine, and cell surface proteins were labeled with NHS-biotin. In transfected cells both before and after activation of calpain by agonist exposure, NR2A was found in the intracellular fraction and in the cell surface fraction (Fig. 5A). Actin, a marker of intracellular proteins and a control for cell lysis, remained almost exclusively in the intracellular fraction even after agonist exposure (Fig. 5A). After activation of calpain, levels of NR2A decreased in both the intracellular fraction (50\% decrease from the 0 min control) $(n=8 ; p=0.0166)$ (Fig. $5 A, B)$ and the extracellular fraction ( $45 \%$ decrease from the 0 min control) $(n=8 ; p=$ 0.0172 ) (Fig. $5 A, B$ ). This shows that activation of calpain leads to NR2A degradation in both cellular compartments. When co- 

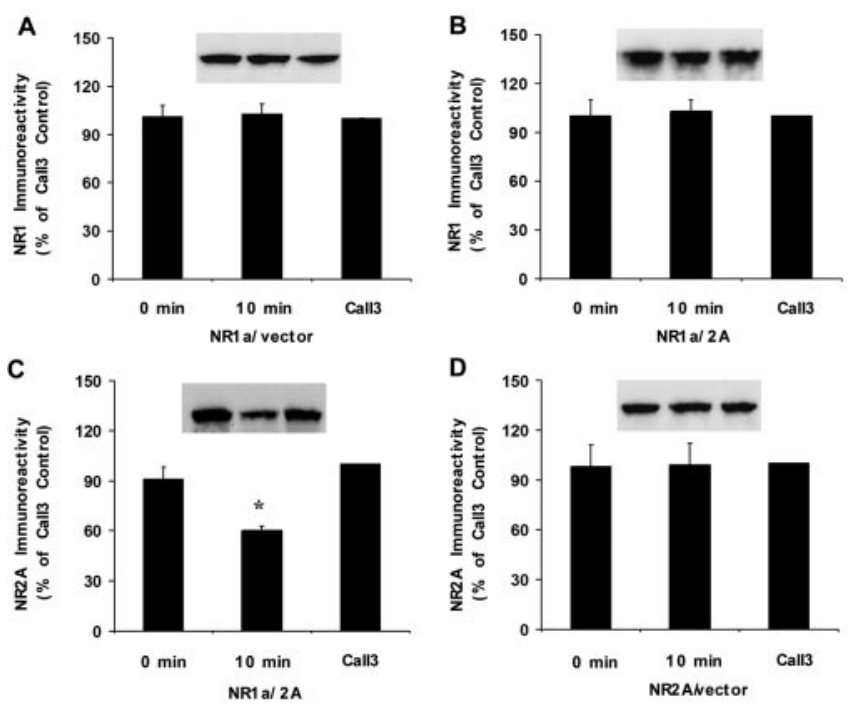

E

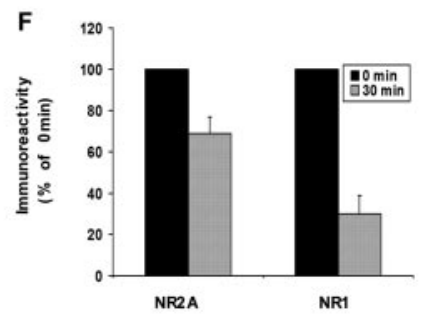

Figure 6. Assembly of NR1 and NR2 subunits is required for calpain-mediated cleavage. HEK293 cells cotransfected with different combinations of NMDA receptor subunits were treated with $1 \mu \mathrm{m}$ ionomycin for $10 \mathrm{~min}$ to activate calpain and analyzed by Western blots. NR1 and NR2A immunoreactivities were quantitated as a percentage of the Call3. Data are shown as mean \pm SEM (error bars). NR1 was not cleaved by calpain whether it was present alone $(A)$ or assembled with NR2A ( $B)$. In contrast, the level of NR2A significantly decreased after ionomycin treatment when associated with NR1 ( $31 \%$ decrease from $0 \mathrm{~min})(n=6 ; p=0.0132)$. This was inhibited by the inclusion of Call3 $(n=6 ; p=0.018)$ ( $(C$. No degradation of NR2A was found in transfections including NR2A alone $(n=5 ; p=0.31)(D)$, showing that only coassembled NMDA receptors are affected by calpain. E, HEK293 cells cotransfected with the NR1a/2A combination were treated with $100 \mu \mathrm{m}$ glutamate and $100 \mu \mathrm{m}$ glycine for $30 \mathrm{~min}$ and then subjected to immunoprecipitation. An anti-NR2A antibody (N-terminal antibody A-6475) was used for immunoprecipitation, and the resulting blots were probed with both NR2A and NR1 antibodies. Input, Total cell lysate; IP-NR2A, immunoprecipitated fraction. Representative Western blots show a significant decrease in NR1 and NR2A levels. F, Quantification of NR2A and NR1 levels in the immunoprecipitated fraction. Agonist treatment resulted in a 72\% decrease in NR1 immunoreactivity $(n=3 ; p=0.0088)$ and a $31 \%$ decrease in NR2A immunoreactivity compared with 0 min $(n=3 ; p=0.012)$, suggesting that NR1 is also destroyed when associated with NR2A that is degraded by calpain. Data are shown as mean \pm SEM (error bars).

transfected with PSD-95, the decline of NR2A levels was abolished in both the intracellular fraction $(n=7 ; p=0.4754)$ (Fig. $5 C, D)$ and the extracellular fraction $(n=7 ; p=0.9247)$ (Fig. $5 C, D)$. These data demonstrate that PSD-95 protects NR2A from calpain-mediated cleavage in both cellular compartments.

Assembly of NR1 and NR2 subunits in the endoplasmic reticulum is necessary for NMDA receptors to reach the cell surface and to form a functional ion channel (Mcllhinney et al., 1996, 1998, Okabe et al., 1999; Standley et al., 2000). To investigate whether assembly with an NR1 subunit is a prerequisite for the cleavage of the NR2 subunit by calpain and also to extend the locations of NR2A cleavage, we transfected different combinations of NR1 and NR2 subunits. HEK293 cells cotransfected with NR1a/2A or NR2A-vector were treated with $1 \mu \mathrm{M}$ ionomycin (a calcium ionophore) for $10 \mathrm{~min}$ to activate calpain and analyzed by Western blots (Guttmann et al., 2002). When cotransfected with NR1, the level of NR2A significantly decreased after ionomycin treatment compared with the 0 min time point $(n=6 ; p=$ 0.0132 ) (Fig. 6C); this decrease was inhibited by the inclusion of CalI3 ( $n=6 ; p=0.018$ ) (Fig. $6 C$ ). No degradation of NR2A was found in transfections including NR2A alone $(n=5 ; p=0.3084)$ (Fig. 6D). NR1 was not significantly degraded when present in homomeric or heteromeric transfections $(n=6 ; p>0.05)$ (Fig. $6 A, B)$. This shows that association of NR1 with NR2 leading to exit from the ER is necessary for cleavage of NR2A, consistent with our previous data that calpain-mediated cleavage affects physiologically active, coassembled receptors (Guttmann et al., 2002).

The failure of NR1 levels to decline in transfected cells with ionomycin exposure and with NMDA receptor activation shows that it is not likely to be a direct calpain substrate in situ. NR1 is also not a calpain substrate in vitro (Guttmann et al., 2001). This, however, leads to the question of the disposition of NR1 (likely a small portion of the total NR1) that is associated with cleaved NR2. In neurons, most of the cleaved NR2B remains on the cell surface at least temporarily, and NR1 levels do not decline (Simpkins et al., 2003). However, in transfected cells, NR2 subunit levels decrease on the cell surface, and the number of functional receptors declines, suggesting that NR1 is also destroyed or internalized. Therefore, we examined the effect of calpain activation (through glutamate and glycine application) on NR1 levels in the NR2A-associated pool (via coimmunoprecipitation using an NR2A antibody). The NR1 selectively associated with NR2A also declined ( $72 \%$ decrease from $0 \mathrm{~min})(n=3 ; p=0.0088)$ (Fig. $6 E, F)$, accompanying the decrease in NR2A (31\% decrease from $0 \min )(n=3 ; p=0.012)$. This shows that the NR1 subunit, although it does not appear to be a calpain substrate itself, is destroyed in association with NR2A destruction by calpain.

\section{Mechanism of PSD-95-mediated effects on calpain cleavage} Although one major function of PSD-95 is the structural attachment of multiple receptors and receptor clustering, a second is its ability to modulate receptor turnover and endocytosis. PSD-95 might alter either or both of these in its modulation of calpainmediated cleavage of NR2. To test this possibility, HEK293 cells were cotransfected with the NR1a/2A combination and wild-type dynamin or K44A dynamin, a dominant negative form of dynamin that inhibits endocytosis of NMDA receptors and other receptors by clathrin-coated pits (Ceresa et al., 1998; Lin et al., 2000; Roche et al., 2001). Activation of calpain by agonist treatment significantly decreased NR2A immunoreactivity (32\% of the $0 \mathrm{~min})$ in dynamin-cotransfected cells $(n=5 ; p=0.0335)$ (Fig. 7A). Cotransfection of this mutant dynamin form had no effect on calpain-mediated breakdown of NR2A (31\% of the 0 $\min )(n=5 ; p=0.0385)$ (Fig. $7 B)$ and did not consistently result in the appearance of novel products. Similar results were seen with concanavalin A, another inhibitor of clathrin-mediated endocytosis (Shiina et al., 2001). NR1a/2A-transfected HEK293 cells were pretreated with concanavalin A $(0.25 \mathrm{mg} / \mathrm{ml})$ for 30 min and subsequently exposed to glutamate and glycine. Concanavalin A pretreatment did not change the cleavage pattern of NR2A by calpain $(n=4 ; p=0.0036$ for control group; $p=0.0102$ for concanavalin A group; 0 vs $30 \mathrm{~min}$ ) (Fig. 7C,D). These data indicate that the blockade of NMDA receptor internalization does not alter calpain-mediated cleavage of NR2A in this system and thus is not likely to be a mechanism involved in the protection by PSD-95 of NR2A cleavage by calpain.

Another mechanism by which PSD-95 might block cleavage of NR2A is through structural interactions. We sought to assess 

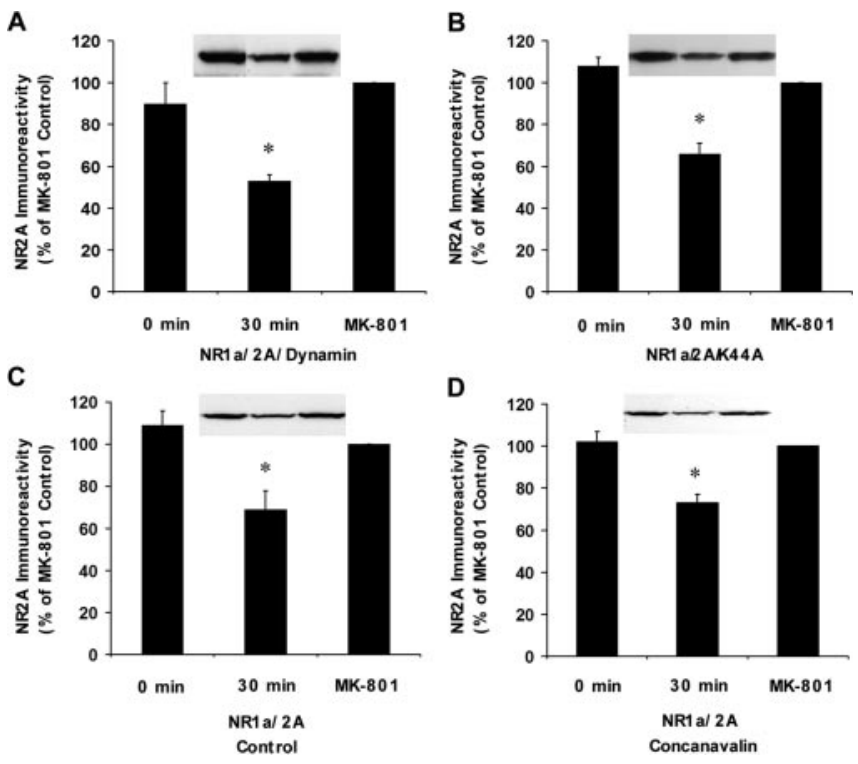

Figure 7. Blockade of NMDA receptor internalization does not alter calpain-mediated cleavage. HEK293 cells cotransfected with the NR1a/2A combination and wild-type dynamin or K44A dynamin were treated with $100 \mu \mathrm{m}$ glutamate and $100 \mu \mathrm{m}$ glycine in the presence or absence of $100 \mu \mathrm{M}$ MK-801 for 0 or $30 \mathrm{~min}$ and analyzed by Western blotting. The amount of NR2A immunoreactivity was quantified as a percentage of the MK-801 control condition. Agonist treatment caused a significant decrease in NR2A immunoreactivity ( $32 \%$ decrease from $0 \mathrm{~min}$ ) in dynamin-cotransfected cells $(n=5 ; p=0.034)(A)$, whereas cotransfection of the mutant dynamin form K44A had no effect on calpain-mediated breakdown of NR2A (31\% decrease from $0 \mathrm{~min})(n=5 ; p=0.038)(B)$ and did not result in appearance of novel products. $C, D$, NR1a/2A-cotransfected HEK293 cells were pretreated with concanavalin A $(0.25 \mathrm{mg} / \mathrm{ml})(D)$ or vehicle ( $($ ) for $30 \mathrm{~min}$ and exposed to $100 \mu \mathrm{m}$ glutamate and $100 \mu \mathrm{m}$ glycine in the presence or absence of $100 \mu \mathrm{m}$ MK-801. No difference was found in the cleavage pattern of NR2A by calpain after concanavalin A pretreatment ( $n=4 ; p=0.0102 ; 0 \mathrm{vs} 30 \mathrm{~min}$ ) compared with the control group $(n=4 ; p=0.0036)$. Data are shown as mean \pm SEM (error bars).

whether clustering of PSD-95 and NR2A, a process mediated by lipid interactions in heterologous systems, might control the blockade of calpain-mediated cleavage. Palmitoylation of PSD-95 occurs through specific cysteines at amino acids 3 and 5 (Craven et al., 1999). When PSD-95 mutated at these sites $(\mathrm{C} 3,5 \mathrm{~S})$ was cotransfected with NR1a/2A, and calpain was activated by exposure to glutamate and glycine, PSD-95 no longer blocked NR2A breakdown, and clustering of PSD-95 and NR2A no longer was present (supplemental Fig. 1, available at www. jneurosci.org as supplemental material). The level of NR2A in both the intracellular and extracellular fractions decreased compared with 0 min (Fig. $8 A, B)(n=6 ; p=0.021$ for intracellular fraction; $n=6 ; p=0.0285$ for extracellular fraction). However, immunoprecipitation with an anti-NR2A antibody revealed that PSD-95 and NR2A did not remain associated under these conditions (Fig. 8C), as reported previously for potassium channels in transfected cells and for NR2 subunits when palmitoylation is blocked in neurons (Topinka and Bredt, 1998; Li et al., 2003). These data show that the ability to associate with the NMDA receptor and the ability to cluster are features of PSD-95 that control calpain-mediated cleavage of NR2A. To separate these related possibilities, we examined the ability of SAP102, an NR2binding membrane-associated guanylate kinase (MAGUK) protein containing PDZ domains similar to those of PSD-95 but lacking the palmitoylation motifs and the ability to cluster in heterologous systems (Lau et al., 1996; Muller et al., 1996; ElHusseini et al., 2000), to protect NR2A from cleavage by calpain. When HEK293 cells cotransfected with the NR1a/2A combina-
A
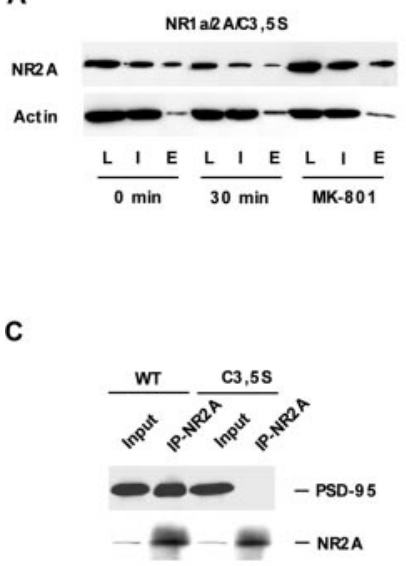

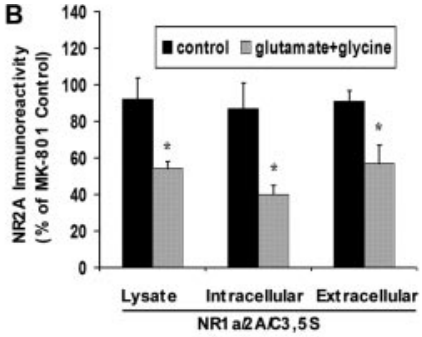

D

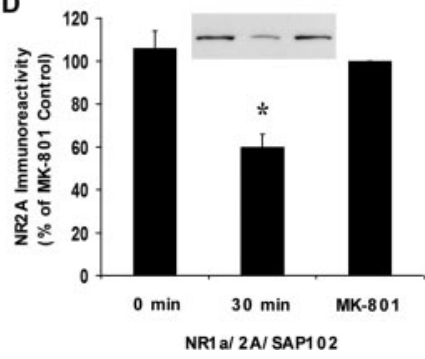

Figure 8. PSD-95 clustering and its association with NMDA receptors are required for the PSD-95-mediated effect. HEK293 cells cotransfected with the NR1a/2A combination and wildtype (WT) PSD-95 or mutant PSD-95 (C3,5S) were treated with $100 \mu \mathrm{m}$ glutamate and $100 \mu \mathrm{m}$ glycine in the presence or absence of $100 \mu \mathrm{M}$ MK-801 for 0 or 30 min and then labeled with NHS-biotin under nonlytic conditions. The extracellular and intracellular fragments were separated and subjected to Western blotting with an N-terminal antibody for NR2A (A-6475). The amount of immunoreactivity in the lysate (L), extracellular (E), and intracellular (I) fractions was quantified as a percentage of the MK-801 control condition. In cells transfected with PSD-95 $(C 3,5 S)$, a representative Western blot and bar graph $(A, B)$ demonstrate reduced levels of NR2A immunoreactivity after calpain activation in the intracellular fraction (47\% decrease from the 0 min control) $(n=6 ; p=0.021)$ and the extracellular fraction (34\% decrease from the 0 min control) $(n=6 ; p=0.0285)$, showing that the PSD-95 mutant $(C 3,5 S)$ does not block calpainmediated cleavage of NR2A in either the intracellular and extracellular fractions. An anti-actin antibody confirmed that actin remains primarily in the intracellular fraction. C, HEK293 cells cotransfected with the NR1a/2A combination and wild-type PSD-95 (WT) or mutant PSD-95 $(C 3,5 S)$ were immunoprecipitated with an anti-NR2A antibody. Input, Total cell lysate; IPNR2A, immunoprecipitated fraction. The resulting blots were probed with both NR2A and PSD-95 antibodies. Representative Western blots show the disruption of the NR2A-PSD-95 interaction by transfection with PSD-95 (C3,5S). D, HEK293 cells cotransfected with the NR1a/2A combination and SAP102 were treated with $100 \mu \mathrm{m}$ glutamate and $100 \mu \mathrm{m}$ glycine in the presence or absence of $100 \mu \mathrm{m}$ MK-801 for 0 or $30 \mathrm{~min}$ and analyzed by Western blotting. The amount of NR2A immunoreactivity was quantified as a percentage of the MK-801 control condition. Cotransfection with SAP102 did not protect NR2A from calpain-mediated cleavage (46\% decrease from $0 \mathrm{~min})(n=5 ; p=0.025)$. Data are expressed as mean \pm SEM (error bars).

tion and SAP102 were treated with glutamate and glycine, the presence of SAP102 did not block calpain-mediated cleavage of NR2A $(n=5 ; p=0.025)$ (Fig. $8 D)$. This shows that palmitoylation of PSD-95 (and likely resultant clustering) in conjunction with direct attachment to NR2A mediates the ability of PSD-95 to block calpain-mediated cleavage of NR2A.

\section{PSD-95-NR2A interactions in neurons}

In our previous studies, we noted that although NR2B is readily cleaved by calpain in neurons, NR2A could not readily be cleaved (Simpkins et al., 2003). The association of NR2A with synapses and thus with PSD-95 could explain this phenomenon. Because PSD-95 expression level and its association with NMDA receptors increases with development (Sans et al., 2000), we examined the ability of NR2A to be cleaved at different time points in development in cultured cortical neurons. In contrast to our previous studies in hippocampal neurons (conducted at $\geq 18$ DIV), NR2A was cleaved by calpain in younger cultures (14-16 DIV) (Fig. 9A). As neurons matured (22-24 DIV), the amount of NR2A that could be cleaved decreased (Fig. 9A). Because NR2A 


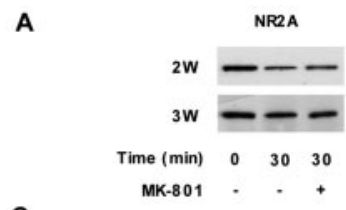

C
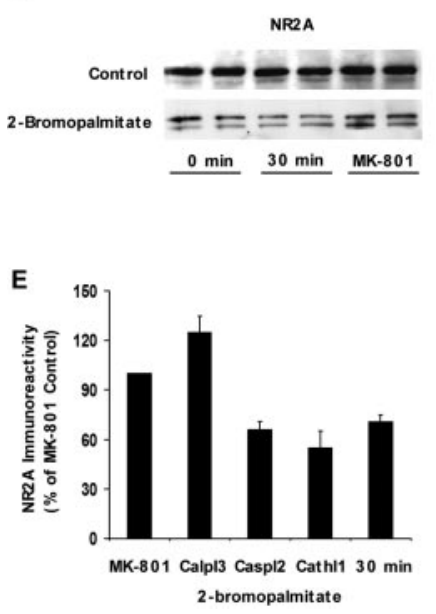

Figure 9. Inhibition of palmitoylation regulates the susceptibility of NR2A to be cleaved by calpain. $A$, Representative Western blot demonstrating the developmental decrease in NR2A cleavage by calpain in cortical neurons. Cortical neurons from different ages were exposed to NMDA receptor agonist stimulation over a 0 or 30 min time course and subjected to Western blots. NR2A was cleaved by calpain at 2 weeks ( $2 \mathrm{~W}$ ) and became uncleavable after 3 weeks (3W) of development. The inclusion of MK- 801 prevented the loss of NR2A during agonist treatment. $B$, Representative Western blot showing coimmunoprecipitation of NR2A and PSD-95. Cortical neurons ( $\geq 22$ DIV) were treated with $100 \mu \mathrm{m}$ 2-bromopalmitate or control (vehicle only) for 10 hr. NR2A was immunoprecipitated, and samples were immunoblotted with PSD-95 antibody. 2-Bromopalmitate treatment disrupted the interaction of PSD-95 and NR2A (left lane, control; right lane, 2-bromopalmitate). Equivalent amounts of NR2A were precipitated in each condition. C, Representative Western blot showing the cleavage of NR2A after 30 min agonist stimulation after $100 \mu \mathrm{m}$ 2-bromopalmitate treatment. D, Quantification of NR2A levels. Treatment with 2-bromopalmitate increased the amount of NR2A cleaved to $34 \%$ (of 0 min) ( $n=6 ; p=$ 0.0092 ) compared with the control group ( $10 \%$ decrease from $0 \mathrm{~min}$ ); the inclusion of MK-801 prevented the loss of NR2A. $E$, Identification of the protease involved in NR2A breakdown. Cortical neurons preincubated with 2-bromopalmitate were treated with $100 \mu \mathrm{m}$ glutamate and glycine for $30 \mathrm{~min}$ in the presence of Call3, Caspl2, or Cathl1. Inclusion of Call3 ( $p=0.0002$ by ANOVA; $n=6 ; p=0.0090$; (all3 vs $30 \mathrm{~min}$ ) but not inhibitors of caspase or cathepsin prevented the loss of NR2A ( $n=6 ; p>0.05$ for both). Data are expressed as mean \pm SEM (error bars).

expression and PSD-95 expression concurrently increase in these cultures over this period (data not shown) (as is also seen in hippocampal neurons) (Sans et al., 2000), the increase in PSD95-NR2A interactions could mediate this decreased susceptibility to calpain.

We then examined the effect of palmitoylation blockade on the cleavage of NR2A in cultured cortical neurons. Blockade of palmitoylation prevents clustering of PSD-95 in model systems, and in neurons in culture, it disperses PSD-95 from synapses and thus dissociates NR2A from PSD-95 (Li et al., 2003). When we pretreated cultured cortical neurons (22-24 DIV) for $10 \mathrm{hr}$ with $100 \mu \mathrm{M} 2$-bromopalmitate, a palmitoylation inhibitor, treatment of cultures with glutamate and glycine decreased the level of NR2A by $34 \%$ compared with $0 \min (n=6 ; p=0.0092)$ (Fig. $9 C, D)$. No significant reduction was observed in the control group (vehicle only). Immunoprecipitation with an anti-NR2A antibody revealed that 2-bromopalmitate treatment dissociated PSD-95 and NR2A. Equal amounts of NR2A were precipitated in each condition (Fig. 9B). Inclusion of CalI3 ( $p=0.0002$ by
ANOVA; $n=6 ; p=0.0090$ Call3 vs $30 \mathrm{~min}$ ) but not inhibitors of caspase or cathepsin prevented the loss of NR2A $(n=6 ; p>0.05$ for both) (Fig. 9E). This confirms that the interactions of PSD-95 and NR2A are crucial to protection of NR2A from calpainmediated cleavage in neurons and again mechanistically link this protection with palmitoylation of PSD-95 and direct interaction with NR2A.

\section{Discussion}

In this study, we have demonstrated that interactions of the NR2 subunit with PSD-95 control calpain-mediated degradation of NR2. Both NR2A and NR2B degradation is inhibited by coexpression of PSD-95, whereas the degradation of NR2 subunits lacking the PSD-95-binding motif is unaffected by coexpression of PSD-95. The effect of PSD-95 is mediated not only at the cell surface but also at internal cellular locations, more characteristic of a direct biochemical blockade of cleavage than an alteration of NR2 trafficking by PSD-95. The lack of effect of blockade of internalization on calpain-mediated cleavage of NR2 also suggests that the effects of PSD-95 represent a biochemical phenomenon rather than a PSD95-mediated alteration of NR2 trafficking. These interactions explain the resistance of NR2A to calpain-mediated proteolysis in neurons because dissociation of the PSD-95-NR2 linkage creates NR2A that can be destroyed in a calpain-dependent manner.

PSD-95 and its homologues induce the clustering of NMDA receptors (Kim et al., 1996) and block the internalization of NMDA receptors in heterologous systems (Roche et al., 2001). The present study suggests that clustering of PSD-95-NMDA receptor complexes (which in heterologous systems requires palmitoylation of PSD-95 and direct interaction of PSD-95 with NR2) controls calpain-mediated degradation of NR2. Removal of the ESDV motif on NR2 (which removes NR2A-PSD-95 interactions) removes the ability of PSD-95 to block NR2 cleavage. In addition, interference with palmitoylation of PSD-95 in HEK cells and in neurons allows NR2 subunits to be cleaved by calpain, but this process dissociates NR2A from PSD-95. However, SAP102 does not block calpain-mediated cleavage, showing that simply binding to NR2A (as SAP102 is capable of) is insufficient to block calpain-mediated cleavage (Muller et al., 1996; Lau et al., 1996; El-Husseini et al., 2000). SAP102 differs from PSD-95 in several ways, including the inability to cluster receptors in heterologous systems. Thus, the clustering ability of PSD-95 may be an additional feature beyond the ability to bind NR2A that regulates calpain-mediated cleavage of NR2A.

These findings explain our results showing that NR2B is readily cleaved by calpain after NMDA receptor activation in hippocampal neurons, but NR2A is more resistant, even though both subunits are degraded in vitro and in heterologous systems (Guttmann et al., 2001, 2002; Simpkins et al., 2003). The NR2B subunit predominates in extrasynaptic membranes and is more associated with SAP102 in synapses in hippocampal neurons in culture (Sans et al., 2000). NR2A is predominant in synaptic membranes, where it is presumably associated with PSD-95 (Li et al., 1998; Tovar and Westbrook, 1999). This provides one explanation for the selective cleavage of NR2B by calpain in hippocampal neurons and suggests that one function of calpain in neurons could be to cleave extrasynaptic receptors while sparing synaptic receptors. Interestingly, NR2A is also less susceptible to proteosomal degradation than $\mathrm{NR} 2 \mathrm{~B}$ and is internalized less readily (Ehlers, 2003; Lavezzari et al., 2004). Whether these processes are linked to calpain-mediated events is unclear.

Because palmitoylation and clustering of PSD-95 appear to be crucial for its ability to block calpain-mediated cleavage, this ef- 
fect may be mediated through steric hindrance as a consequence of PSD-95-NR2 interactions (Kornau et al., 1995; Niethammer et al., 1996). Alternatively, the effect of PSD-95 binding on calpainmediated NR2 degradation could reflect facilitation of other processes. Phosphorylation by PKC, Src, or Fyn differentially modulates the susceptibility of the NMDA receptor to calpain in vitro (Bi et al., 1998a; Rong et al., 2001). PSD-95 links Fyn-tyrosine kinase to NR2A subunits and enhances phosphorylation of NR2A (Tezuka et al., 1999). PSD-95 also associates with other members of the Src family of protein-tyrosine kinases, including Src, Yes, and Lyn (Tezuka et al., 1999), and the brain-specific protein-tyrosine phosphatase $\zeta$ (Kawachi et al., 1999). SAP102 binds distinct kinases from PSD-95, suggesting an additional or alternative mechanism by which SAP102 fails to block calpain-mediated cleavage of NR2 (Kalia and Salter, 2003). Thus, the effect of PSD-95 on calpain-mediated cleavage of NR2 could result from phosphorylation and/or direct effects of steric hindrance.

Because calpain is activated during synaptic transmission (Vanderklish et al., 1995), the interaction of PSD-95 and NR2 subunits could stabilize NMDA receptors in the postsynaptic membrane during synaptic transmission and other times during which intracellular calcium levels rise. In neurons in which PSD-95 is depleted or absent, PSD-95 may not be necessary for stability of synaptic NMDA receptors, and other signaling molecules may be functionally upregulated to compensate for the role of PSD-95 (Sattler et al., 1999). Interaction with PSD-95 has been identified as a factor controlling internalization and electrophysiology of NMDA receptors in several paradigms (Roche et al., 2001; Li et al., 2003). Our studies demonstrate rapid cleavage of NR2B in neurons with production of a relatively stable NR2B product. This breakdown product is present in cultured neurons at low levels before application of agonists, rapidly increases in amount during NMDA receptor activation, and is blocked by NMDA receptor inhibition. The fragment remains on the cell surface during glutamatergic stimulation (Simpkins et al., 2003). Although we cannot exclude the possibility that, under basal conditions, the breakdown product is produced only within a small subpopulation of neurons, it seems more likely that it is produced by ongoing NMDA receptor stimulation. Recent data from others explain how calpain cleavage would play a role in NMDA receptor turnover. NMDA receptor turnover is typically slow, although defined pathways now exist for NMDA receptor internalization (Scott et al., 2004). Although NR2B contains an internalization motif in the last 20 amino acids of the C-terminal region, NR1 and NR2A contain such motifs only in the region of the proximal $\mathrm{C}$ terminus adjacent to the membrane. NR2B also contains a second internalization motif in a similar location (Scott et al., 2004). Motifs in the proximal C terminus direct internalized receptors to destructive endosomes, whereas the internalization motif in the distal C terminus of NR2B directs receptors to recycling endosomes. Calpain-mediated cleavage of NR2 subunits would expose the proximal C terminus and facilitate rapid internalization of NR1 and NR2 subunits to destructive endosomes.

The results from the HEK293 model system generally match those from neurons, but HEK cell experiments have more flexibility for investigating the biochemistry of calpain-mediated cleavage of NMDA receptors. When cleaved in the C-terminal region, $\mathrm{NR} 2 \mathrm{~A}$ and $\mathrm{NR} 2 \mathrm{~B}$ remain active but may be modulated differently by second messenger systems and freed from synaptic linking elements. These active receptors can remain on the cell surface, as in hippocampal neurons, or be readily destroyed, as occurs in HEK293 cells (Guttmann et al., 2002; Simpkins et al., 2003). In the present study, no N-terminal fragment of NR2B can be found in HEK293 cells, even though cleavage of NR2B by calpain in neurons creates a stable N-terminal fragment. This suggests that the $\mathrm{N}$-terminal products of calpain-mediated cleavage are readily susceptible to further degradation in heterologous systems. In addition, these studies in HEK cells confirm the region of NR2A that is cleaved by calpain in situ. NR2A is cleaved by calpain at amino acids 1279 and 1330 in vitro, and truncation of the receptor to amino acid 1051 removes physiological effects of calpain activation on NMDA receptor properties and in vitro cleavage (Guttmann et al., 2001, 2002). The present data show that cleavage of NR2A in situ occurs in the region containing the two in vitro sites. Truncation to amino acid 1330 removes most of the cleavage of NR2A by calpain, and the remainder is removed by truncation to amino acid 1279 . This suggests that all of the calpain sites are found in the region from amino acids 1279-1464 of NR2A, consistent with in vitro data (Guttmann et al., 2001).

Although calpain is traditionally viewed as a plasma membrane-associated enzyme, it also acts at internal membranes in physiological and pathophysiological situations (Hood et al., 2004). PSD-95 protects NR2 from cleavage intracellularly and at the cell surface, perhaps reflecting the observation that MAGUK proteins interact with NMDA receptors early in their trafficking (Standley et al., 2000). Although calpain could act in concert with internalization, cleavage of substrates by calpain does not appear to require internalization. NR1 itself is not a calpain substrate but is destroyed when associated with NR2 as levels of NR1 that coimmunoprecipitate with NR2 decrease with calpain activation. Thus, NR2 turnover may regulate NR1 destruction in heterologous expression systems, consistent with observations that NR1 turnover occurs through two separate pools (Huh and Wenthold, 1999).

A previous study reported that coexpression of PSD-95 increases NR2 levels in transfected HEK293 cells and that deletion of the C-terminal ESDV motif eliminates the effect of PSD-95 (Rutter and Stephenson, 2000). Blockade of calpain-mediated cleavage provides one mechanism for this effect. PSD-95 did not globally inhibit calpain activity in HEK293 cells because PSD-95 had no effect on degradation of spectrin by calpain and on the degradation of truncated forms of NR2A. In addition, cotransfection with PSD-95 does not alter the size of the intracellular calcium response to agonists, which agrees with an electrophysiological study by Yamada et al. (1999). Although PSD-95 may decrease the sensitivity of NR1a/2A receptors to glutamate (Rutter and Stephenson, 2000), our assays are performed at saturating concentrations of agonists such that little change in calpain activation is likely to be noted.

Although calpain is viewed as a mediator of excitotoxicity, the present results suggest that calpain activation could be protective against excitotoxicity in some situations by promoting NMDA receptor destruction. This appears to be true in heterologous systems, in which calpain inhibition increases the speed of NMDA receptor-mediated cell death (Guttmann et al., 2002). However, in neurons, calpain is but one step in a destructive process, and cleaved NR2B receptors remain active on the surface (Simpkins et al., 2003). Thus, the direct protective effect of calpain in excitotoxicity may vary among different paradigms.

In summary, interactions of the NR2 subunit and PSD-95 control calpain-mediated degradation of the NR2 subunit. In conjunction with the direct degradation of other synaptic proteins by calpain, these results provide mechanisms by which cal- 
pain can modulate the turnover of synaptic and extrasynaptic NMDA receptors.

\section{References}

Anegawa NJ, Guttmann RP, Grant ER, Anand R, Lindstrom J, Lynch DR (2000) N-Methyl-D-aspartate receptor mediated toxicity in nonneuronal cell lines: characterization using fluorescent measures of cell viability and reactive oxygen species production. Brain Res Mol Brain Res 77:163-175.

Bi R, Bi X, Baudry M (1998a) Phosphorylation regulates calpain-mediated truncation of glutamate ionotropic receptors. Brain Res 797:154-158.

Bi X, Rong Y, Chen J, Dang S, Wang Z, Baudry M (1998b) Calpainmediated regulation of NMDA receptor structure and function. Brain Res 790:245-253.

Ceresa BP, Kao AW, Santeler SR, Pessin JE (1998) Inhibition of clathrinmediated endocytosis selectively attenuates specific insulin receptor signal transduction pathways. Mol Cell Biol 18:3862-3870.

Cho KO, Hunt CA, Kennedy MB (1992) The rat brain postsynaptic density fraction contains a homolog of the Drosophila discs-large tumor suppressor protein. Neuron 9:929-942.

Choi DW (1988) Glutamate neurotoxicity and diseases of the nervous system. Neuron 1:623-634.

Collingridge GL, Lester RA (1989) Excitatory amino acid receptors in the vertebrate central nervous system. Pharmacol Rev 41:143-210.

Craven SE, El-Husseini AE, Bredt DS (1999) Synaptic targeting of the postsynaptic density protein PSD-95 mediated by lipid and protein motifs. Neuron 22:497-509.

Ehlers MD (2003) Activity level controls postsynaptic composition and signaling via the ubiquitin-proteasome system. Nat Neurosci 6:231-242.

El-Husseini AE, Topinka JR, Lehrer-Graiwer JE, Firestein BL, Craven SE, Aoki C, Bredt DS (2000) Ion channel clustering by membraneassociated guanylate kinases: differential regulation by $\mathrm{N}$-terminal lipid and metal binding motifs. J Biol Chem 275:23904-23910.

Estus S, Tucker HM, van Rooyen C, Wright S, Brigham EF, Wogulis M, Rydel RE (1997) Aggregated amyloid- $\beta$ protein induces cortical neuronal apoptosis and concomitant "apoptotic" pattern of gene induction. J Neurosci 17:7736-7745.

Gallagher MJ, Huang H, Grant ER, Lynch DR (1997) The NR2B-specific interactions of polyamines and protons with the $N$-methyl-D-aspartate receptor. J Biol Chem 272:24971-24979.

Grant ER, Bacskai BJ, Anegawa NJ, Pleasure DE, Lynch DR (1998) Opposing contributions of NR1 and NR2 to protein kinase C modulation of NMDA receptors. J Neurochem 71:1471-1481.

Grant ER, Guttmann RP, Seifert KM, Lynch DR (2001) A region of the rat $\mathrm{N}$-methyl-D-aspartate receptor $2 \mathrm{~A}$ subunit that is sufficient for potentiation by phorbol esters. Neurosci Lett 310:9-12.

Guttmann RP, Baker DL, Seifert KM, Cohen AS, Coulter DA, Lynch DR (2001) Specific proteolysis of the NR2 subunit at multiple sites by calpain. J Neurochem 78:1083-1093.

Guttmann RP, Sokol S, Baker DL, Simpkins KL, Dong Y, Lynch DR (2002) Proteolysis of the $\mathrm{N}$-methyl-D-aspartate receptor by calpain in situ. J Pharmacol Exp Ther 302:1023-1030.

Hollmann M, Heinemann S (1994) Cloned glutamate receptors. Annu Rev Neurosci 17:31-108.

Hood JL, Brooks WH, Roszman TL (2004) Differential compartmentalization of the calpain/calpastatin network with the endoplasmic reticulum and Golgi apparatus. J Biol Chem 279:43126-43135.

Huh KH, Wenthold RJ (1999) Turnover analysis of glutamate receptors identifies a rapidly degraded pool of the $N$-methyl-D-aspartate receptor subunit, NR1, in cultured cerebellar granule cells. J Biol Chem 274:151-157.

Kalia LV, Salter MW (2003) Interactions between Src family protein tyrosine kinases and PSD-95. Neuropharmacology 45:720-728.

Kawachi H, Tamura H, Watakabe I, Shintani T, Maeda N, Noda M (1999) Protein tyrosine phosphatase zeta/RPTPbeta interacts with PSD-95/ SAP90 family. Brain Res Mol Brain Res 72:47-54.

Kim E, Cho KO, Rothschild A, Sheng M (1996) Heteromultimerization and NMDA receptor-clustering activity of Chapsyn-110, a member of the PSD-95 family of proteins. Neuron 17:103-113.

Kistner U, Wenzel BM, Veh RW, Cases-Langhoff C, Garner AM, Appeltauer U, Voss B, Gundelfinger ED, Garner CC (1993) SAP90, a rat presynaptic protein related to the product of the Drosophila tumor suppressor gene dlg-A. J Biol Chem 268:4580-4583.
Kohr G, Seeburg PH (1996) Subtype-specific regulation of recombinant NMDA receptor-channels by protein tyrosine kinases of the src family. J Physiol (Lond) 492:445-452.

Kohr G, Jensen V, Koester HJ, Mihaljevic AL, Utvik JK, Kvello A, Ottersen OP, Seeburg PH, Sprengel R, Hvalby O (2003) Intracellular domains of NMDA receptor subtypes are determinants for long-term potentiation induction. J Neurosci 23:10791-10799.

Kornau HC, Schenker LT, Kennedy MB, Seeburg PH (1995) Domain interaction between NMDA receptor subunits and the postsynaptic density protein PSD-95. Science 269:1737-1740.

Lau LF, Mammen A, Ehlers MD, Kindler S, Chung WJ, Garner CC, Huganir RL (1996) Interaction of the $N$-methyl-D-aspartate receptor complex with a novel synapse-associated protein, SAP102. J Biol Chem 271:21622-21628.

Lavezzari G, McCallum J, Dewey CM, Roche KW (2004) Subunit-specific regulation of NMDA receptor endocytosis. J Neurosci 24:6383-6391.

Li B, Otsu Y, Murphy TH, Raymond LA (2003) Developmental decrease in NMDA receptor desensitization associated with shift to synapse and interaction with postsynaptic density-95. J Neurosci 23:11244-11254.

Li JH, Wang YH, Wolfe BB, Krueger KE, Corsi L, Stocca G, Vicini S (1998) Developmental changes in localization of NMDA receptor subunits in primary cultures of cortical neurons. Eur J Neurosci 10:1704-1715.

Liao GY, Wagner DA, Hsu MH, Leonard JP (2001) Evidence for direct protein kinase-C mediated modulation of $N$-methyl-D-aspartate receptor current. Mol Pharmacol 59:960-964.

Lin JW, Ju W, Foster K, Lee SH, Ahmadian G, Wyszynski M, Wang YT, Sheng M (2000) Distinct molecular mechanisms and divergent endocytotic pathways of AMPA receptor internalization. Nat Neurosci 3:1282-1290.

Lu X, Rong Y, Bi R, Baudry M (2000) Calpain-mediated truncation of rat brain AMPA receptors increases their Triton X-100 solubility. Brain Res 863:143-150.

Lynch DR, Guttmann RP (2001) NMDA receptor pharmacology: perspectives from molecular biology. Curr Drug Targets 2:215-231.

Lynch DR, Anegawa NJ, Verdoorn T, Pritchett DB (1994) N-Methyl-Daspartate receptors: different subunit requirements for binding of glutamate antagonists, glycine antagonists, and channel-blocking agents. Mol Pharmacol 45:540-545.

McIlhinney RA, Molnar E, Atack JR, Whiting PJ (1996) Cell surface expression of the human $\mathrm{N}$-methyl-D-aspartate receptor subunit la requires the co-expression of the NR2A subunit in transfected cells. Neuroscience 70:989-997.

McIlhinney RA, Le Bourdelles B, Molnar E, Tricaud N, Streit P, Whiting PJ (1998) Assembly intracellular targeting and cell surface expression of the human $N$-methyl-D-aspartate receptor subunits NR1a and NR2A in transfected cells. Neuropharmacology 37:1355-1367.

Meldrum B, Garthwaite J (1990) Excitatory amino acid neurotoxicity and neurodegenerative disease. Trends Pharmacol Sci 11:379-387.

Mori H, Manabe T, Watanabe M, Satoh Y, Suzuki N, Toki S, Nakamura K, Yagi T, Kushiya E, Takahashi T, Inoue Y, Sakimura K, Mishina M (1998) Role of the carboxy-terminal region of the GluR epsilon2 subunit in synaptic localization of the NMDA receptor channel. Neuron 21:571-580.

Muller BM, Kistner U, Kindler S, Chung WJ, Kuhlendahl S, Fenster SD, Lau LF, Veh RW, Huganir RL, Gundelfinger ED, Garner CC (1996) SAP102, a novel postsynaptic protein that interacts with NMDA receptor complexes in vivo. Neuron 17:255-265.

Niethammer M, Kim E, Sheng M (1996) Interaction between the C terminus of NMDA receptor subunits and multiple members of the PSD-95 family of membrane-associated guanylate kinases. J Neurosci 16:2157-2163.

Okabe S, Miwa A, Okado H (1999) Alternative splicing of the C-terminal domain regulates cell surface expression of the NMDA receptor NR1 subunit. J Neurosci 19:7781-7792.

Omkumar RV, Kiely MJ, Rosenstein AJ, Min KT, Kennedy MB (1996) Identification of a phosphorylation site for calcium/calmodulin dependent protein kinase II in the NR2B subunit of the $N$-methyl-D-aspartate receptor. J Biol Chem 271:31670-31678.

Roberts-Lewis JM, Savage MJ, Marcy VR, Pinsker LR, Siman R (1994) Immunolocalization of calpain I-mediated spectrin degradation to vulnerable neurons in the ischemic gerbil brain. J Neurosci 14:3934-3944.

Roche KW, Standley S, McCallum J, Dune Ly C, Ehlers MD, Wenthold RJ (2001) Molecular determinants of NMDA receptor internalization. Nat Neurosci 4:794-802. 
Rong Y, Lu X, Bernard A, Khrestchatisky M, Baudry M (2001) Tyrosine phosphorylation of ionotropic glutamate receptors by Fyn or Src differentially modulates their susceptibility to calpain and enhances their binding to spectrin and PSD-95. J Neurochem 79:382-390.

Rutter AR, Stephenson FA (2000) Co-expression of postsynaptic density-95 protein with NMDA receptors results in enhanced receptor expression together with a decreased sensitivity to L-glutamate. J Neurochem 75:2501-2510.

Sans N, Petralia RS, Wang YX, Blahos II J, Hell JW, Wenthold RJ (2000) A developmental change in NMDA receptor-associated proteins at hippocampal synapses. J Neurosci 20:1260-1271.

Sattler R, Xiong Z, Lu WY, Hafner M, Macdonald JF, Tymianski M (1999) Specific coupling of NMDA receptor activation to nitric oxide neurotoxicity by PSD-95 protein. Science 284:1845-1848.

Scott DB, Michailidis I, Mu Y, Logothetis D, Ehlers MD (2004) Endocytosis and degradative sorting of NMDA receptors by conserved membraneproximal signals. J Neurosci 24:7096-7109.

Shiina T, Arai K, Tanabe S, Yoshida N, Haga T, Nagao T, Kurose H (2001) Clathrin box in $\mathrm{G}$ protein-coupled receptor kinase 2. J Biol Chem 276:33019-33026.

Simpkins KL, Guttmann RP, Dong Y, Chen Z, Sokol S, Neumar RW, Lynch DR (2003) Selective activation induced cleavage of the NR2B subunit by calpain. J Neurosci 23:11322-11331.

Sprengel R, Suchanek B, Amico C, Brusa R, Burnashev N, Rozov A, Hvalby O, Jensen V, Paulsen O, Andersen P, Kim JJ, Thompson RF, Sun W, Webster LC, Grant SG, Eilers J, Konnerth A, Li J, McNamara JO, Seeburg PH
(1998) Importance of the intracellular domain of NR2 subunits for NMDA receptor function in vivo. Cell 92:279-289.

Standley S, Roche KW, McCallum J, Sans N, Wenthold RJ (2000) PDZ domain suppression of an ER retention signal in NMDA receptor NR1 splice variants. Neuron 28:887-898.

Steigerwald F, Schulz TW, Schenker LT, Kennedy MB, Seeburg PH, Kohr G (2000) C-terminal truncation of NR2A subunits impairs synaptic but not extrasynaptic localization of NMDA receptors. J Neurosci 20:4573-4581.

Tezuka T, Umemori H, Akiyama T, Nakanishi S, Yamamoto T (1999) PSD-95 promotes Fyn-mediated tyrosine phosphorylation of the $N$-methyl-D-aspartate receptor subunit NR2A. Proc Natl Acad Sci USA 96:435-440.

Topinka JR, Bredt DS (1998) N-terminal palmitoylation of PSD-95 regulates association with cell membranes and interaction with $\mathrm{K}+$ channel Kv1.4. Neuron 20:125-134.

Tovar KR, Westbrook GL (1999) The incorporation of NMDA receptors with a distinct subunit composition at nascent hippocampal synapses in vitro. J Neurosci 19:4180-4188.

Vanderklish P, Saido TC, Gall C, Arai A, Lynch G (1995) Proteolysis of spectrin by calpain accompanies theta-burst stimulation in cultured hippocampal slices. Brain Res Mol Brain Res 32:25-35.

Yamada Y, Chochi Y, Takamiya K, Sobue K, Inui M (1999) Modulation of the channel activity of the epsilon2/zetal-subtype $N$-methyl-D-aspartate receptor by PSD-95. J Biol Chem 274:6647-6652.

Yang M, Leonard JP (2001) Identification of mouse NMDA receptor subunit NR2A C-terminal tyrosine sites phosphorylated by co-expression with v-Src. J Neurochem 77:580-588. 